\title{
A Huge Aneurism of Ascending Thoracic Aorta
}

\author{
Andi Kacani ${ }^{1}$, Saimir Kuci ${ }^{2}$, Arber Aliu ${ }^{1}$, Alfred Ibrahimi ${ }^{2}$, Aferdita Veseli ${ }^{1}$, Arben Baboci ${ }^{1}$
}

Received: 21 June 2021 / Accepted: 02 July 2021 / Published online: 20 July 2021

This article is published with open access at https://journal.astes.org.al

(C) The author(s) 2021.\& Copyright (C) 2021, the Albanian Society for Trauma and Emergency Surgery

(a) The Albanian Journal of Trauma and Emergency Surgery is an Open Access Journal. All articles are distributed under the terms of the Creative Commons Attribution Non-Commercial License: http://creativecommons.org/licenses/by-nc/4.0/) which permits unrestricted non-commercial use, distribution, and reproduction in any medium provided the original work is properly cited.

\begin{abstract}
Giant Ascending Aorta Aneurysm (AAA) is a rare condition, because of early diagnosis incidence appears to be increasing as a result of routine screening, increased clinical awareness, and improved imaging modalities. The etiology of aneurysms involving the aortic root and ascending aorta can be genetically triggered, degenerative or atherosclerotic, inflammatory, or can result from infectious diseases. According to many studies for ascending aortic aneurysms larger than $6 \mathrm{~cm}$ the risk of rupture, dissection, or deaths was 15.6, making it a large life-threatening aneurysm.

We present the case of a Giant AAA of about $8,7 \mathrm{~cm}$ diameter in a 68 years old man who was successfully operated on for ascending aorta and aortic root replacement under modified Bentall technique using composite mechanical conduit with coronary reimplantation.

Conclusion: Ascending giant aortic aneurysm is a rare finding, varying from asymptomatic clinical presentation. Surgical treatment remains the standard treatment with very good results. The selection of the operating technique is very individual, depending on the case and the experience of the surgeon.
\end{abstract}

Key words: Aorta Aneurysm. Cardiac surgery. Bentall technique.

\section{Introduction}

Giant Ascending Aorta Aneurysm (AAA) is a rare condition, because of early diagnosis incidence appears to be increasing as a result of routine screening, increased clinical awareness and improved imaging modalities. Etiology of aneurysms involving the aortic root and ascending aorta can be genetically triggered, degenerative or atherosclerotic, inflammatory, or can result from infection diseases [1, 2, 3]. According to many studies for ascending aortic aneurysms larger than $6 \mathrm{~cm}$ the risk of rupture, dissection, or deaths was 15.6, making it a large life threating aneurysm [4, 5]. About technique choosing for repairing of the aortic root, using the

Original article, no submission or publication in advance or in parallel

* Corresponding author: Andi Kacani MD, Ph.D.

$\bowtie$ akacani@yahoo.com

1 Department of Cardiac Surgery, University Hospital Centre "Mother Theresa", Tirana, ALBANIA

2 Department of Cardiac Anesthesia, University Hospital Centre "Mother Theresa", Tirana, ALBANIA composite graft replacement, for patients in whom an aortic valve sparing root repair is not suitable, Modified Bentall

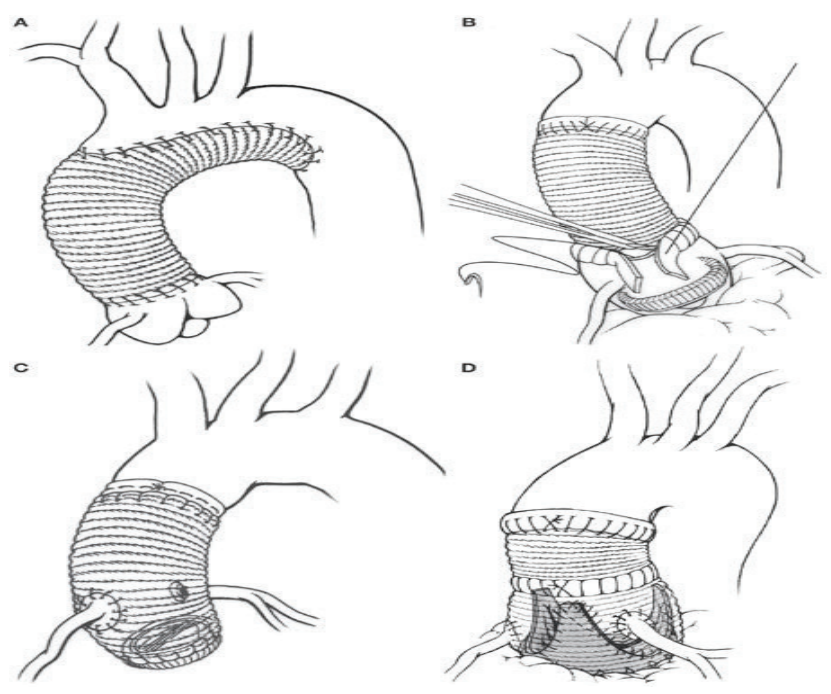

Fig 1; Surgical techniques for the treatment of the ascending aorta, and when accompanied by aortic root replacement: $A$ - Ascending aortic and hemiarch replacement; $B$ - Ascending aortic replacement; $C$-Modified Bentall procedure; D "Valve-Sparing” according to Yako David 
technique is the technique of choice, with excellent results. In this case, the aortic valve leaflets may be normal, but there is a loss of the sinotubular junction because of the dilation of the aorta $[6,7]$. This may lead to insufficient coaptation of the leaflets and therefore cause valve-regurgitation.

Preoperative assessment of patients requiring aortic root and ascending surgery generally includes a transthoracic echocardiography, and either an Angio CT-scan imaging to obtain all necessary information on the entire thoracic aorta. Proper description of the aortic dilation is necessary to optimally plan the procedure, especially the level of the distal anastomosis. In patients younger than 40 years angiography is not performed.

\section{Case Report}

S.B, 68 years-old man was admitted to our hospital because of abnormal chest computed tomography (CT) findings. With no prior medical history, only 3 months history of progressive dyspnea especially last two weeks, associated with chest discomfort. He had suffered from hypertension for many years with an irregular antihypertensive treatment and a long history of smoking. On examination, he had diastolic murmur, hemodynamically stable, other system examinations were normal, complete blood count, biochemical and cardiac enzymes analyses were also normal. Computed Tomography CT Angiography showed a huge ascending aortic aneurism $87 \times 84 \mathrm{~mm}$, aortic bulb $67 \mathrm{~mm}$, arch 44-35 mm, descendent part $28 \mathrm{~mm}$, abdominal aorta $25 \mathrm{~mm}$, with no evidence for dissection. (Fig 2)

Coronary angiography resulted with no significant stenosis. Cardiac echography; Hypertrophic LV, DTD 70 $\mathrm{mm}$, EF $50 \%$, severe regurgitation of aortic tricuspid valve, ascending aorta $87 \mathrm{~mm}$, aortic bulb $67 \mathrm{~mm}$, aortic annulus $28 \mathrm{~mm}$, light mitral regurgitation, PSAP $25 \mathrm{mmHg}$. ECHO Doppler of carotid artery without significant stenosis. ECG RS, SV1-V3, RV4-V6

Because of root enlargement and AI not restorable, root reconstruction with aortic valved graft SJM Nr 27 with coronary reimplantation, Bentall Procedure was scheduled.

After median sternotomy a huge aorta was detected, aortic-monocaval cannulation was performed, crystalloid cardioplegia solution $800 \mathrm{ml}$ as first dose and normothermic blood cardioplegia 3 X $600 \mathrm{ml}$. Aortic valve and ascendant aorta from aortic root to brachiocephalic trunk origin was excised. The patient underwent Bentall Procedure with aortic valved graft SJM nr 27 and coronary reimplantation. (fig. 3) Extracorporeal circulation time 165min, Cross clamp time $115 \mathrm{~min}$. Chest tube drainage was $550 \mathrm{ml}$, extubating time was 6 hours and discharged from ICU after 40 hours.
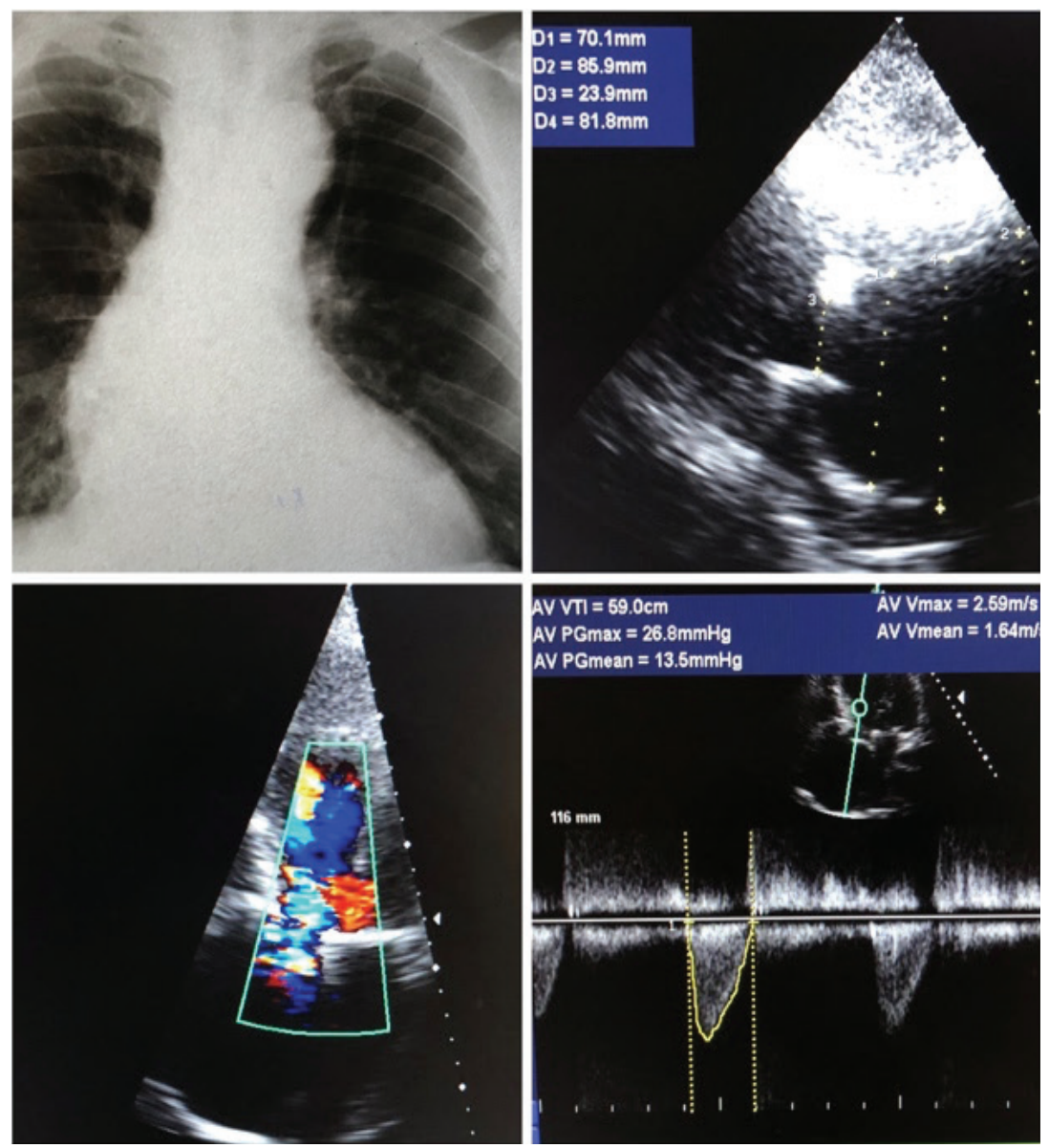

Figure 2. ECHO Doppler of carotid artery without significant stenosis. ECG $R S, S V 1-V 3, R V 4-V 6$ 

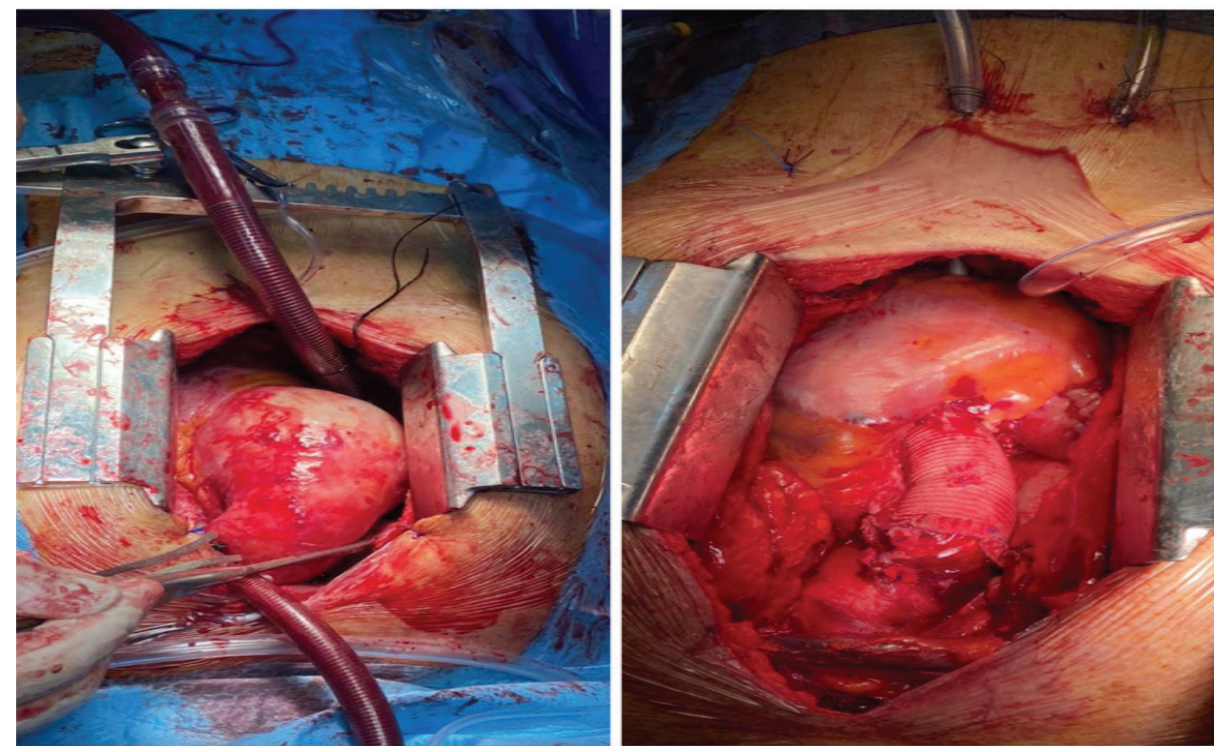

Figure 3; Intraoperative photo before and after ascending aorta, its root and valve replacement according to modified Bentall procedure

Post-operative Echocardiography resulted aortic valvular prothesis mean gradient $10 \mathrm{mmHg}$, Gmax $=16 \mathrm{mmHg}$, $\mathrm{Vmax}=2.0 \mathrm{~m} / \mathrm{s}$

The patient was uneventfully discharged on postoperative day 8 .

Weight $96 \mathrm{~kg}$, Height $180 \mathrm{~cm}$

\section{Discussion}

We can find Giant aneurysms in various presentations. Major complications include dissection and rupture [8]. However, an asymptomatic giant thoracic aneurysm is extremely rare.

According to the famous Lawrence Cohn book, Cardiac surgery in the adult most TAAs occur in the ascending aorta $65 \%$ followed by the descending thoracic aorta $35 \%$, and the aortic arch $10 \%$. The average age at the time of diagnosis is around the 60-70 years range. Cystic medial necrosis is the most common pathological reason of aortic aneurysms.

In ascending aortic aneurysms and moreover giant ones, studies and dilemmas of the surgeon are related to the level of the anastomoses as these determine not only the type and success of the interventions but also the long-term results and reintervention need.

The purpose of the intervention is to replace the entire dilated aorta and perform a healthy anastomosis to reduce the risk of further dilatation or rupture in the border areas. Therefore, as we have said before, the examinations are very important to decide the strategy and the type of interventions that we will perform.

If the aortic arch is dilated, this part of the aorta must also be replaced and a complete or partial 1 aortic arch replacement may need to be performed. To accomplish this, we implement the most contemporary technique: circulatory arrest with selective anterograde perfusion of the brain, in moderate hypothermia (temp. 28 degrees Celsius) [9]. This technique, unlike the deep hypothermia technique, carries less risk of neurological complications and hemorrhage. In the last decade the reported results for the technique with moderate hypothermia are very encouraging, neurological events less than $2 \%$ in elective cases. However, in our case, as evidenced by the examinations performed, it is not necessary to replace the aortic arch and make circulatory arrest, which minimizes the risk of neurological events.

In the replacement of the root and the ascending aorta, very good results have been given by the valve-sparing technique of "preserving the valve" of the aorta with implantation of the coronary ostia and replacement of the ascending aorta, according to Yacoub or David [10, 11]. But which is preferred in elective cases, with intact aortic cusp without dilatation of the aortic root and with moderate to moderate aortic regurgitation. This technique carries the risk of interventions for aortic valve insufficiency. The degree of aortic root dilatation and valve insufficiency are important indicators of the success of the intervention and the long-term outcome.

In the planned cases the in-operator mortality is about $1.5-2.0 \%$ comparable to the cases with replacement of the isolated aortic valve [12].

Another discussion is the level of the proximal anastomosis which determines the type of intervention that we will perform. In the case of aortic and root replacement, the "modified Bentall" technique (with valved conduit) remains the "Gold Standard". This is the procedure we performed even after the aortic root and Valsalva's sinuses are very dilated, and the aortic valve insufficiency is advanced [7]

Lim et al. in his study of 120 cases where both techniques were used, Bentall and David, with a 5-year follow-up [13]. There was no significant change in mortality 
$88.4 \pm 5.2 \%$ in the Bentall group and $90.8 \pm 4.4 \%$ in the "valve-sparing" group. Moreover, there was a higher incidence of re-interventions in cases of "valve-sparing" as a result of the recurrence of severe aortic insufficiency. The authors recommend caution in decision-making in cases of severe aortic valve regurgitation.

On the contrary Dias et al. reports significantly more complications associated with mechanical prosthesis in the Bentall technique than in that with aortic valve preservation "David procedure" and with a difference in mortality in 7-year follow-up [14].

However, the introduction of the Bentall technique with conduit grafts with biological valve has minimized the risk of hemorrhage in patients over 65 years of age.

\section{Conclusion}

Ascending giant aortic aneurysm is a rare finding, with varying from asymptomatic clinical presentation. Surgical treatment remains the standard treatment with very good results. The selection of the operating technique is very individual, depending on the case and the experience of the surgeon.

COI Statement: This paper has not been submitted in parallel. It has not been presented fully or partially at a meeting or podium or congress. It has not been published nor submitted for consideration beforehand.

This research received no specific grant from any funding agency in the public, commercial, or non-profit sectors. There are no relevant or minor financial relationships from authors, their relatives or next of kin with external companies.

Disclosure: The authors declared no conflict of interest. No funding was received for this study.

Acknowledgement: We would like to thank medical staff of Department of Cardiac Surgery and Cardiac Anesthesia, at University Hospital Centre "Mother Theresa", Tirana, ALBANIA.

\section{References}

1. Larson EW, Edwards WD: Risk factors for aortic dissection: A necropsy study of 161 cases. Am J Cardiol 1984; 53:849.

2. Pressler V, McNamara JJ: Thoracic aortic aneurysm: Natural history and treatment. J Thorac Cardiovasc Surg 1980; 79:489.

3. Pressler V, McNamara JJ: Aneurysm of the thoracic aorta: Review of 260 cases. J Thorac Cardiovasc Surg 1985; 89:50.

4. Cheung K., Boodhwani M., Chan K., Beauchesne L., Dick A., Coutinho T. Thoracic aortic aneurysm growth: role of sex and aneurysm etiology. J. Am. Heart Assoc. 2017;6

5. Braunwald, Bonow, Mann, Zipes, Libby: Heart Desease, Deseases of Aorta 2012,1306-1949 Aortic replacement: Comparison of clinical outcomes between different surgical techniques. European Journal of Cardio-Thoracic Surgery, Volume 46, Issue 4, October 2014, Pages 685-692

6. Aortic replacement: Comparison of clinical outcomes between different surgical techniques. European Journal of CardioThoracic Surgery, Volume 46, Issue 4, October 2014, Pages 685-692

7. Bentall H, De Bono A. A technique for complete replacement of the ascending aorta, Thorax, 1968, vol. 23 (pg. 338-9)

8. Davies RR, Goldstein LJ, Coady MA, et al: Yearly rupture or dissection rate for thoracic aortic aneurysms. Simple prediction based on size. Ann. Thoracic surg 2002, 73:1727

9. Fiore A, Grande AM, Pellegrini C, Viganò M. A time bomb in the thorax: the giant ascending aortic aneurysm: case report. $\mathrm{G}$ Chir. 2012; 33: 24-25.

10. David TE, Feindel CM. An aortic valve-sparing operation for patients with aortic incompetence and aneurysm of the ascending aorta, J Thorac Cardiovasc Surg, 1992, vol. 103 (pg. 617-21) discussion 22

11. Sarsam MA, Yacoub M. Remodeling of the aortic valve anulus, J Thorac Cardiovasc Surg, 1993, vol. 105 (pg. 435-8)

12. Paterick TE, Ammar KA, Jan MF, Loberg R, Buch M, Khandheria BK, Tajik AJ. Aortopathies: etiologies, genetics, differential diagnosis, prognosis and management. Am J Med 2013; 126: 670-8

13. Lim JY, Kim JB, Jung SH, SJ, Chung CH, Lee JW. Surgical management of aortic root dilatation with advanced aortic regurgitation: Bentall operation versus valve-sparing procedure, Korean J Thorac Cardiovasc Surg, 2012, vol. 45 (pg. 141-7)

14. Dias RR, Mejia OA, Fiorelli AI, Pomerantzeff PM, Dias AR, Mady C, et al. Analysis of aortic root surgery with composite mechanical aortic valve conduit and valve-sparing reconstruction, Rev Bras Cir Cardiovasc, 2010, vol. 25 (pg. 491-9) 